\title{
Diastereoselective Synthesis of $\mathbf{C}_{60}$ /Steroid
}

\section{Conjugates}

Alberto Ruiz, ${ }^{\dagger}$ Julieta Coro, ${ }^{\dagger}$ Luis Almagro, ${ }^{\dagger}$ José A. Ruiz, $^{\perp}$ Dolores Molero, ${ }^{\ddagger}$ Enrique E. Maroto, ${ }^{\S}$ Salvatore Filippone, ${ }^{\S}$ María Ángeles Herranz, ${ }^{\S}$ Roberto Martínez-Álvarez, ${ }^{\S}$ Juan Carlos SanchoGarcia, ${ }^{ \pm}$Florent Di Meo, ${ }^{ \pm, \&}$ Margarita Suárez, ${ }^{\dagger}{ }^{\dagger}$ and Nazario Martín. ${ }^{\star}$

† Laboratorio de Síntesis Orgánica, Facultad de Química, Universidad de la Habana, 10400 La Habana, Cuba. E-mail: msuarez@fq.uh.cu

${ }^{\perp}$ Centro de Química Biomolecular. 11600 La Habana, Cuba

‡ C. A. I. de Resonancia, Facultad de Ciencias Químicas, Universidad Complutense de Madrid, 28040 Madrid, Spain

§ Departamento de Química Orgánica I, Facultad de Ciencias Químicas, Universidad Complutense de Madrid, 28040 Madrid, Spain. E-mail: nazmar@quim.ucm.es

${ }^{ \pm}$Departamento de Química-Física, Universidad de Alicante, 03080 Alicante, Spain

\& Laboratoire de Biophysique, Faculté de Pharmacie et Medicine, Université de Limoges, 87025 Limoges, France

\section{TABLE OF CONTENTS}

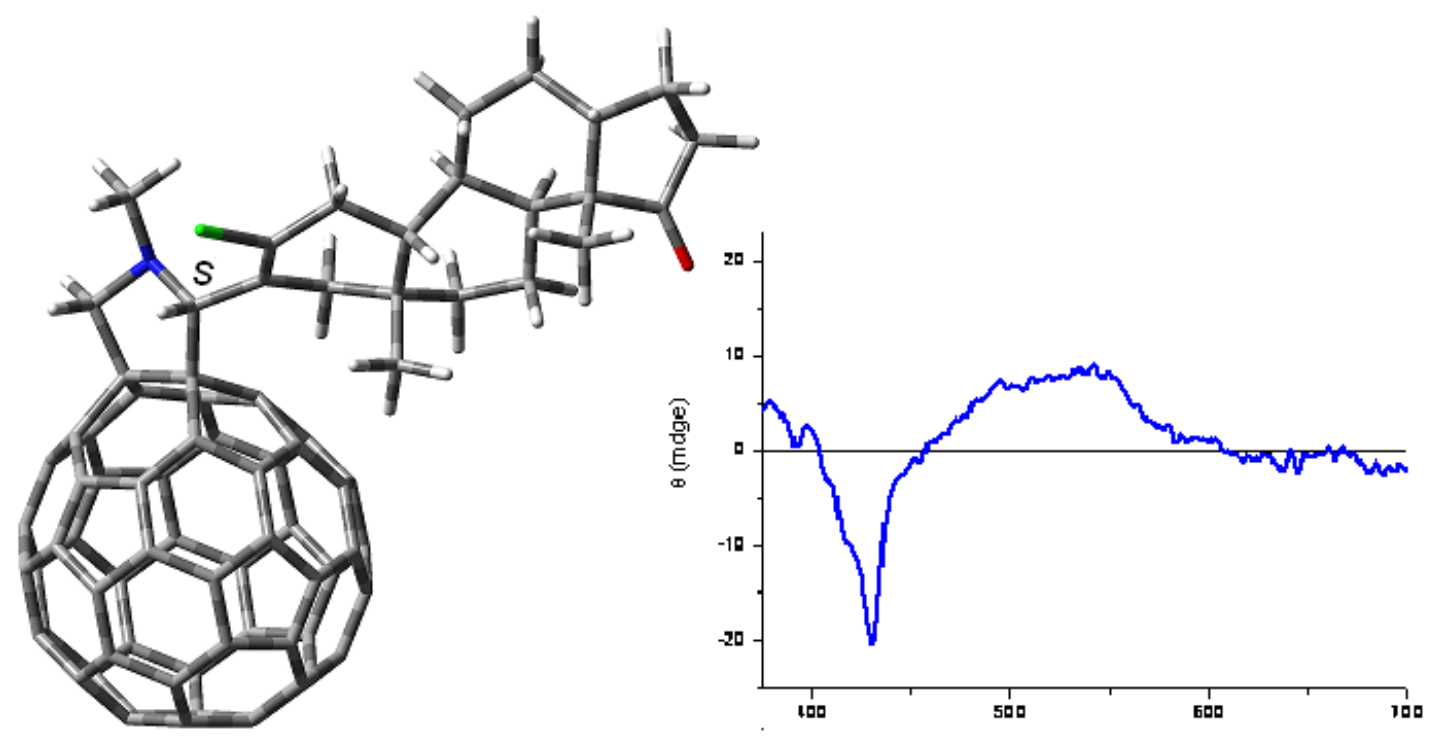




\begin{abstract}
The design and synthesis of fullerene-steroid hybrids by using Prato's protocol has afforded new fullerene derivatives endowed with epiandrosterone, an important naturally occurring steroid hormone. Since the formation of the pyrrolidine ring resulting from the 1,3-dipolar cyloaddition reaction takes place with generation of a new stereogenic center on the $\mathrm{C} 2$ of the five member ring, the reaction proceeds with formation of a diastereomeric mixture [compounds 6 and $\mathbf{7}$ in 70:30 ratio, and 8 and 9 in 26:74 ratio (HPLC)] in which the formation of the major diasteroisomers $\mathbf{6}$ and 9 is consistent with an electrophilic attack of [60]fullerene by the Re face. The chiroptical properties of these conjugates reveal typical Cotton effects in CD spectra that have been used to assign the absolute configuration of the new fulleropyrrolidines. The electrochemical study of the new compounds reveals the presence of four quasi-reversible reduction waves which are cathodically shifted in comparison with the parent $\mathrm{C}_{60}$.
\end{abstract}

\title{
INTRODUCTION
}

Although a large number of reactions with $\mathrm{C}_{60}$ have been reported so far, ${ }^{1}$ stereoselective additions have comparatively been less studied. The addition of azomethine ylides to $\mathrm{C}_{60}$ is one of the most powerful and versatile methods for derivatising fullerenes. ${ }^{2}$ In this regard, condensation of readily available starting materials such as $\alpha$-amino acids and aldehydes gives rise to reactive 1,3-dipoles which efficiently add to $\mathrm{C}_{60}$ leading to functionalised fulleropyrrolidines.

Recently, we have carried out a straightforward procedure catalyzed by silver or copper acetate to efficiently obtain pyrrolidino[60]fullerenes with stereochemical control by enantioselective cycloaddition of $\mathrm{N}$-metalated azomethine ylides to the $\mathrm{C}_{60}$ molecule. ${ }^{3}$ This methodology was later extended to higher fullerenes, developing the first stereoselective cycloaddition of $\mathrm{N}$-metalated azomethine ylides to $\mathrm{C}_{70}$, thus achieving a selective control (site-, regio-, diastereo-, enantiocontrol) in the functionalization of higher fullerenes. ${ }^{4}$ Furthermore, the stereoselective synthesis of $1,3-$ dipolar cycloadditions has also been extended to endohedral fullerenes, namely to a 
La@ ${ }_{72}\left(\mathrm{C}_{6} \mathrm{H}_{3} \mathrm{Cl}_{2}\right)$ derivative. ${ }^{5}$ More recently, we have reported the stereodivergent syntheses of cis/trans pyrrolidino[3,4:1,2]fullerenes and endo/exo pyrrolidines with high enantioselectivity levels. ${ }^{6}$

The formation of fulleropyrrolidines by 1,3-dipolar cycloaddition leads to planar intermediate ylides. Therefore an additional chiral centre on the $\alpha$-amino acid or in the moiety containing the aldehyde group is thus required in order to achieve stereoselection. Thus, Prato et al. had previously applied this reaction to the preparation of chiral fulleroprolines, the absolute configurations of which were determined on the basis of experimental and calculated circular dichroism (CD) spectra. ${ }^{7}$ The diastereoselective synthesis of fulleropyrrolidines endowed with enantiomerically pure functionalized cyclobutanes has also been previously reported. ${ }^{8}$

Recently, the synthesis of diastereoisomerically pure fulleropyrrolidines as chiral platforms for the design of optically active liquid crystals, ${ }^{9}$ and the diasteroselective preparation of fulleroprolines by lithium salt-assisted cycloaddition of azomethine ylides have been reported. ${ }^{10}$

On the other hand, it is well-known that the principal obstacle for the potential use of $\mathrm{C}_{60}$ in biomedical applications is its complete lack of solubility in water and quite low solubility in almost all organic solvents. ${ }^{11}$ The covalent linkage of [60]fullerene with suitably funtionalized molecules is an efficient option to generate functional entities in which each part modulates the properties of the final compound and to achieve solubility. Thus, [60]fullerene has been covalently connected to aminoacids and peptides, ${ }^{12}$ oligonucleoides, ${ }^{13}$ steroids,${ }^{14}$ and imidazonium salts, ${ }^{15}$ among others.

In a previous work, we reported the design of new hybrids fullerene-steroid derivatives by using the Bingel-Hirsch protocol. Interestingly, treatment of [60]fullerene with malonates bearing cholesterol, $\beta$-sitosterol, and ergosterol moieties afforded hybrids exhibiting solubility in a variety of organic solvents. ${ }^{16}$

Continuing our research in the synthesis of a new hybrid functionalized chimeras steroidsfullerenes, in this paper we chose an important steroid for use as steroid platform: the epiandrosterone. This is a steroid hormone with weak androgenic activity and is the natural metabolite of dehydroepiandrosterone via the 5-alpha reductase enzyme, and has been shown to 
naturally occur in most mammals including pigs. ${ }^{17}$ Recent studies have found that epiandrosterone inhibits the pentose phosphate pathway (PPP) and dilates isolated blood vessels pre-contracted by partial depolarization. These results suggest that it may act as an antagonist of L-type $\mathrm{Ca}^{2+}$ channel with properties similar to those of 1,4 -dihydropyridine (DHP) $\mathrm{Ca}^{2+}$ channel blockers. ${ }^{18}$ Also, this steroid can be used as synthetic intermediate for obtaining a wide range of compounds with biological activity, such as aminosteroids which find application as anti-arhythmic, hypotensive, anti-inflammatory, and fungicidal activity. ${ }^{19}$ Another example is the development of steroid-hetero systems (pyridines, thiophene, thiazole and pyrazole) which have potential anti-epileptic, antiprotozoal, antitumor and hypoglycemic bactericidal activities. ${ }^{20}$

Remarkably, there are very few examples of steroid-fullerene hybrids reported so far. One of the first reports being the synthesis of fullerene bisadducts endowed with a steroid molecule. ${ }^{21}$. Other hybrids have also been prepared by Diels-Alder reaction from an steroidal diene and $\mathrm{C}_{60}{ }^{22}$ and by 1,3-dipolar cycloaddition in order to obtain fulleropyrrolidine derivatives. ${ }^{23-26}$ The aim of these investigations are directed to the search for functional hybrid molecules in which the characteristics of fullerenes may be changed, improved their solubility and biocompatibility, thus enabling further biological investigations.

Taking into account the interest on the synthesis of steroids derivatives of fullerenes, here we report on the design of a diasteroselective synthesis of a new type of molecular chimeras through 1,3-dipolar cycloaddition between azomethine ylides (generated in situ) and $\mathrm{C}_{60}$, by treatment of the corresponding formyl-substituted steroid with sarcosine and [60]fullerene by Prato's protocol. The aim is the preparation of new fullerene-steroids hybrids with biological activity which is the ongoing theme of research in our group.

\section{RESULTS AND DISCUSSION}

Nowadays, there is an increasing interest in the combination of two privileged entities on the same scaffold. This procedure leads to hybrid molecules or conjugates with the goal of creating a chemical 
entity whose properties are more effective than its individual components. Ongoing interest in soluble fullerenes, as well as the difficulty of working with this molecular carbon allotrope, in this work we combine [60]fullerene with biologically active steroids.

The fullerene steroids conjugates (6-9) were prepared by Prato reaction by treatment of [60]fullerene with the formyl-containing steroids. Therefore, the first step requires the preparation of the formyl derivatives 4 and 5 (See Scheme 1).

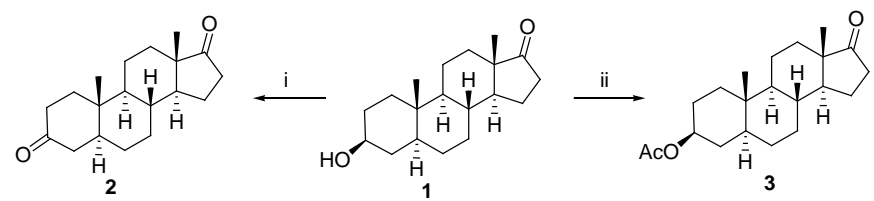

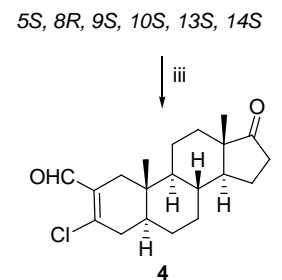

$5 S, 8 R, 9 S, 10 S, 13 S, 14 S$
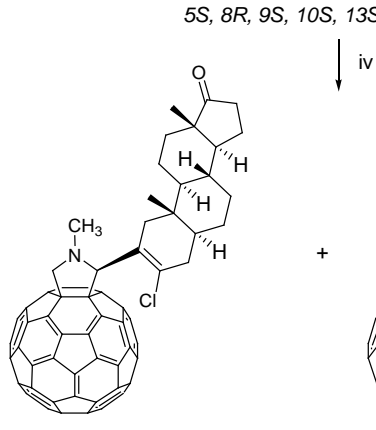

$\downarrow$ iv

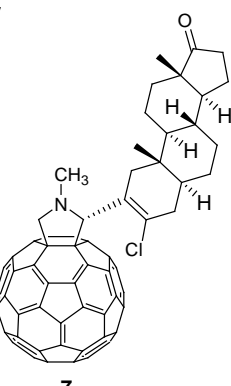

$2 \mathrm{~S}, 5^{\prime} \mathrm{S}, 8^{\prime} R, 9^{\prime} \mathrm{S}, 10^{\prime} \mathrm{S}, 13^{\prime} \mathrm{S}, 14^{\prime} \mathrm{S}$

$3 S, 5 S, 8 R, 9 S, 10 S, 13 S, 14 S$

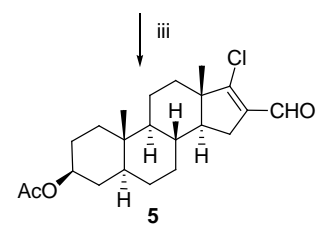

$3 S, 5 S, 8 R, 9 S, 10 S, 13 S, 14 S$

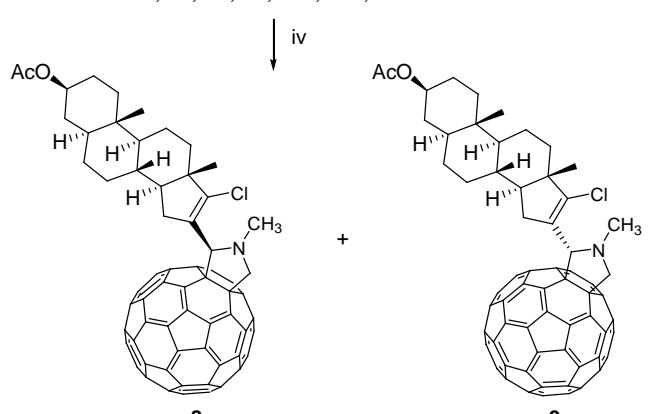

$2 R, 5^{\prime} \mathrm{S}, 8^{\prime} R, 9^{\prime} \mathrm{S}, 10^{\prime} \mathrm{S}, 13^{\prime} \mathrm{S}, 14^{\prime} \mathrm{S}$

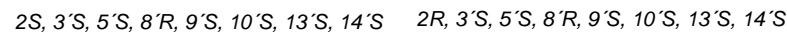

Scheme 1. Synthesis of steroids-[60]fullerenes 6-9. (i) acetone, Jones'reagent, rt; (ii) acetic anhydride, pyridine, rt); (iii) $\mathrm{POCl}_{3}$, DMF, reflux; (iv) $\mathrm{C}_{60}$, N-methylglycine, toluene, reflux.

The convenient transformation of the hydroxyl group on C3 of the epiandrosterone (1) by oxidation gave the $5 \beta$-androstan-3,17-dione (2) and by acetylation gave the $3 \alpha$-acetoxy-5 $\beta$ androstan-17-one (3) both with similar yields to those previously reported. ${ }^{27,28}$ The Vilsmeier-Haack reaction of $\mathbf{2}$ and $\mathbf{3}$ with phosphorus oxychloride and dimethylformamide in refluxing dichlorometane, gave the corresponding 3-chloro-2-formyl-17-oxo-5 $\beta$-androstan-2-ene (4) and 3- $\alpha$ acetoxy-17-chloro-16-formyl-5 $\beta$-androstan-16-ene (5), respectively. The reactions were monitored by TLC and the final compounds were obtained as white solids in good and moderate yields (78\% and 50\%, respectively) after basic hydrolysis with aqueous sodium acetate and purification by flash 
chromatography with a cyclohexane-ethyl acetate (4:1) mixture as the eluent. The new compounds were fully characterized by analytical and spectroscopic techniques (see Experimental Section).

The ${ }^{1} \mathrm{H}-\mathrm{NMR}$ spectra of compounds $\mathbf{4}$ and $\mathbf{5}$ show the signals corresponding to the proton of the formyl group at $\sim 10 \mathrm{ppm}$. The principal differences in the spectrum of $\mathbf{4}$ in comparison with the unmodified steroid 2 resides in the disappearance of the signals corresponding to the methylene protons in C2 of the A ring, and the protons on C1 appear as two doublets at $1.75 \mathrm{ppm}$ and $2.56 \mathrm{ppm}$ $(J=17 \mathrm{~Hz}$ ), which are deshielded in comparison with the same protons in compound 2. The rest of the signals are quite similar in position and multiplicity. ${ }^{13} \mathrm{C}-\mathrm{NMR}$ spectrum of $\mathbf{4}$ shows the carbon of the CHO group at 191.35 ppm and the two new $\mathrm{Csp}^{2}$ on ring A at 133.00 (C2) and 149.57 (C3) ppm.

NMR spectra of compound 5 show the transformation that has occurred in ring D. Signals corresponding to the protons attached to $\mathrm{C} 16$ in the ${ }^{1} \mathrm{H}-\mathrm{NMR}$ spectrum and the signal of the $\mathrm{C}=\mathrm{O}$ group on $\mathrm{C} 17$ in the ${ }^{13} \mathrm{C}$-NMR spectrum disappear and, in the ${ }^{13} \mathrm{C}-\mathrm{NMR}$ spectrum, two new signals assignable to C16 and C17 joined by a double bond at 136.42 ppm and 162.60 ppm respectively, and at $188.15 \mathrm{ppm}$ the signal corresponding to the $\mathrm{CHO}$ group are observed.

The chemical structures of the new compounds were ascertained by MS. Under ESI conditions, compounds 4 and 5 show sodium adducts peaks at $\mathrm{m} / \mathrm{z}=357.2[\mathrm{M}+\mathrm{Na}]^{+}$, and $401.2[\mathrm{M}+\mathrm{Na}]^{+}$, respectively.

The synthesis of N-methyl-2-substituted pyrrolidino[ 3,4:1,2][60]fullerenes was carried out by 1,3-dipolar cycloaddition of the in situ generated azomethine ylides to $C_{60}$ by following Prato's procedure. Thus, a mixture of the corresponding chloroformyl steroid $\mathbf{4}$ or $\mathbf{5}, \mathrm{C}_{60}$, and sarcosine $(\mathrm{N}$ methylglycine) was refluxed in toluene under argon atmosphere for $6 \mathrm{~h}$ (see Scheme 1). The color of the solution changed from purple to brown.

The HPLC chromatogram of the reaction mixture (toluene/acetonitrile 9:1; $1 \mathrm{mLmin}^{-1}$ ) for enantiopure 4, shows peaks at 8.71 and $9.33 \mathrm{~min}$. As the the cyclization to afford the pyrrolidine ring takes place with generation of a new stereogenic center on the C2 of the five member ring, and the 
configuration of the steroid is fixed, the reaction give rise to a diasteromeric mixture of compounds 6 and 7 in 70:30 ratio (HPLC).

Under the same reaction conditions, $\mathbf{5}$ afforded to the mixture of the diasteromers $\mathbf{8}$ and $\mathbf{9}$ with retention time under the same HPLC conditions, of 5.29 and 7.03 min in 26:74 ratio (HPLC). In each of these chromatograms an additional peak, assigned to the $C_{60}$ starting material, appears at 9.84 min, together with other minor peaks attributed to the formation of bis-cycloadducts.

The mixture of diasteromers was easily separated by purification by flash chromatography, initially with carbon disulfide to elute unreacted $\mathrm{C}_{60}$, followed by dichlorometane or toluene, compounds $\mathbf{6}$, 7, 8, and 9 were obtained in 42\%, 31\%, 28\%, and $47 \%$ yields, respectively, as stable brown solids. The moderate stereoselectivity, that affords to the diasteroisomer $\mathbf{6}$ and $\mathbf{9}$ as main products, is consistent with an electrophilic attack of [60]fullerene onto the $R e$ face of the 1,3 dipole. This is probably due to a more stable planar arrangement of the $\pi$ coniugated system, dipole and steroid double bond, in a W shape with respect to the S conformation. In this W conformation, the presence of steroid group hampers the addition from the Si face and favors the approximation from the $R e$ face giving rise the corresponding two diastereoisomers in a 6:4 ratio.
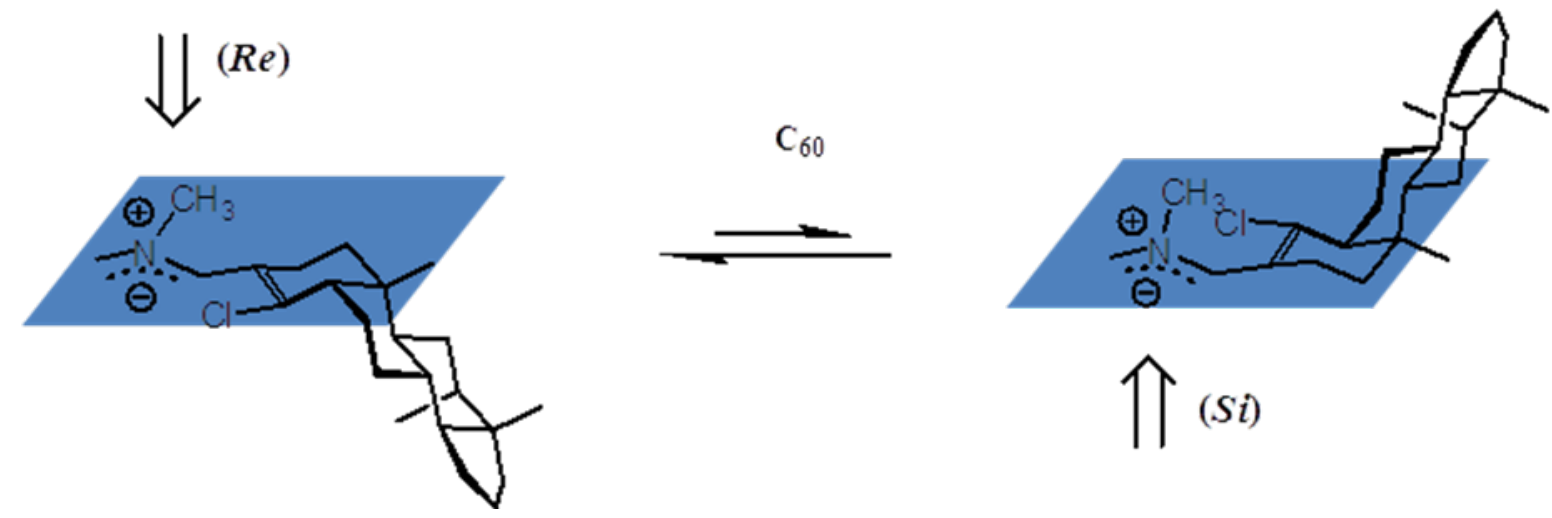

Figure 1. Plausible attack of $\mathrm{C}_{60}$ onto the Re less hindered face of the azomethine-steroid ylide.

${ }^{1} \mathrm{H}$ NMR spectroscopy revealed the presence of $\mathrm{C}_{60}$-steroid hybrids. Besides the disappearance of the formyl proton (signal at $\delta \sim 10 \mathrm{ppm}$ ) in the fulleropyrrolidines $\mathbf{6 , 7 , \mathbf { 8 }}$, and $\mathbf{9}$, new signals corresponding to the protons of the pyrrolidine ring appeare at $\delta 4.16$ and $4.90(\mathbf{6}), \delta 4.18$ and 4.94 (7), $\delta 4.65$ and $4.90(8)$, and $\delta 4.08$ and $4.18(9)$ as doublets ( $J \sim 9 \mathrm{~Hz}$; geminal hydrogens). The 
proton attached to C2 of the pyrrolidine ring is observed at $\delta 5.30$ for $\mathbf{6}$ and $\mathbf{7}$ and $\sim 5.05 \mathrm{ppm}$ for $\mathbf{8}$ and 9. The $N$-methyl protons appear at 2.75 (6), 2.84 (7), $2.83(8)$ and 2.80 (9) ppm. The rest of the signals are in agreement with the data reported for steroids 4 and 5, (see Experimental Section).

On the other hand, the number of signals observed in the ${ }^{13} \mathrm{C}$ NMR spectra reveal the lack of symmetry in these compounds. The ${ }^{13} \mathrm{C}$ NMR spectra of $\mathbf{6}, \mathbf{7}, \mathbf{8}$, and $\mathbf{9}$ show the presence of the signals of the 6,6-ring junction of the $\mathrm{C}_{60}$ framework at $\sim 69 \mathrm{ppm}$ and $\sim 75 \mathrm{ppm}$. For compounds 6 and 7, the signals of the carbons of the fulleropyrrolidine ring appear at 79 ppm (C2) and 70 ppm (C5), while these signals for compounds 8 and $\mathbf{9}$ appear at $\sim 76$ and $\sim 69$ ppm respectively. The positions of the remaining steroid carbon atoms are relatively insensitive to the presence of the $\mathrm{C}_{60}$ cage, and there are no significant variations in the chemical shifts.

MS allowed the proposed structures to be verified. The ESI spectrum for compound $\mathbf{6}$ shows a peak at $\mathrm{m} / \mathrm{z}=1082.22424$ which corresponds to $[\mathrm{M}+\mathrm{H}]^{+}$. The isolation and subsequent fragmentation of this ion under CDI conditions reveals that the retro-Prato reaction cannot take place due to the protonation of the nitrogen atom of the pyrrolidine ring, similarly to other results recently reported by us. ${ }^{29}$ However, in the negative mode of detection the corresponding deprotonated molecule $[\mathrm{M}-\mathrm{H}]^{-}, \mathrm{m} / \mathrm{z}=1081.18888$ undergoes two different fragmentations. The first one corresponds to a loss of a hydrochloride molecule forming a fragment at $\mathrm{m} / \mathrm{z} 1045.21318$. The second fragmentation takes place via a retrocycloaddition process to form a parent fullerene ion at $m / z 719.98761$.

In the ESI positive mode of ionization, compound 7 shows a peak at 1082.22414 corresponding to $[\mathrm{M}+\mathrm{H}]^{+}$. The retrocycloaddition reaction is not observed due to the protonation of the pyrrolidine nitrogen atom.

The MALDI-TOF and ESI mass spectra for compounds 8 and 9 show peaks at $\mathrm{m} / \mathrm{z}=1126.245$ and 1126.25072, respectively, corresponding to the $[\mathrm{M}+\mathrm{H}]^{+}$. The $\mathrm{MS}^{2}$ spectrum reveals a total inhibition of the retrocycloaddition reaction. ${ }^{29}$

We investigated also the possible existence, for each diasteroisomer, of atropoisomers as result of a restricted rotation around the pyrrolidine-steroid bond. To this aim, we performed computational 
studies and variable-temperature NMR experiment with the compounds XXX. The ${ }^{1} \mathrm{H}$ NMR spectra recorded in $\mathrm{CD}_{2} \mathrm{Cl}_{2}$ over a range of temperatures (from $-60{ }^{\circ} \mathrm{C}$ to $70{ }^{\circ} \mathrm{C}$ ) showed only slight changes in the shift of some signals and no dynamic process could be appreciated. Even at $-60{ }^{\circ} \mathrm{C}$, the dynamic exchange between the two potential atropoisomers is enough fast on the NMR timescale and the resulting spectrum is therefore the average of both rotamers.

We have calculated by means of accurate quantum-chemical (Density Functional Theory) methods the (fully relaxed and with a tight grid) torsion energy profiles resulting from single bond rotation around the pyrrolidine-steroid bond, which clearly allows distinguish the existence of a pair of minimum, A and B, at approximately 42 and 190 degrees (see Figure 2). Note that intramolecular (non-covalent) dispersion interactions ${ }^{(\text {Ref1,Ref2) }}$, which are expected to highly influence the mutual orientation between the fullerene and steroid moieties, are explicitly considered into these calculations, and that the cost-effective SVP basis set was considered here although the conclusions are not expected to vary upon further basis set extensions.

However, the energy separation between these two rotamers is close to converge to a value of around $7 \mathrm{kcal} / \mathrm{mol}$, independently of the method chosen, which also include now highly sophisticated DFT-based extensions believed to be of sufficiently large accuracy ${ }^{(\mathrm{Ref3}, \mathrm{Ref4})}$. This is well below of the value reported for related fullerene derivatives which displayed the presence of atropoisomers. Indeed, Nierengarten et al. reported a slow dynamic exchange, observable with NMR experiment, between two atropisomers only at $-40{ }^{\circ} \mathrm{C}$ for an energy barrier of $15 \mathrm{Kcal} / \mathrm{mol} .{ }^{30}$ 

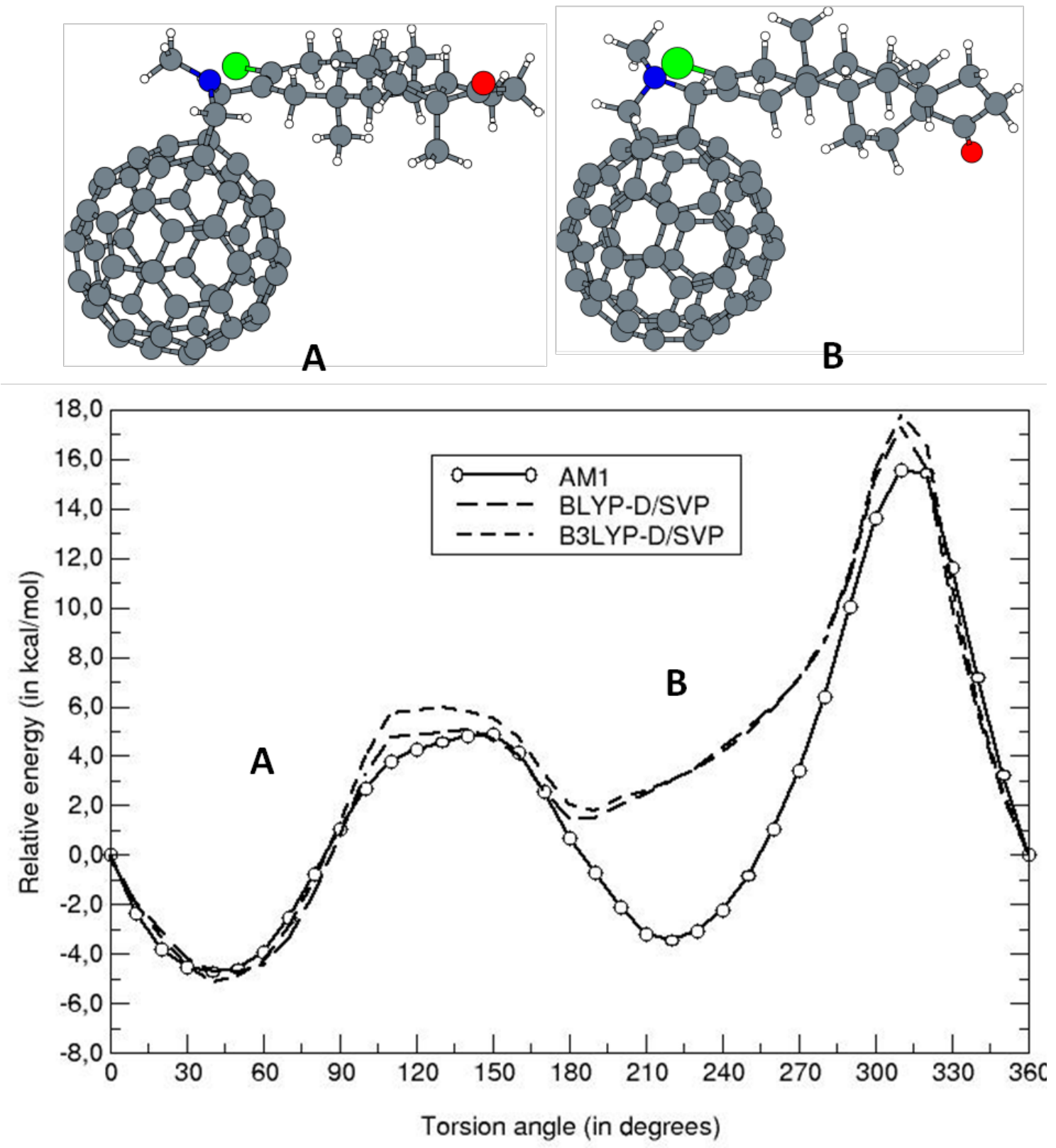

Figure 2. Torsion energy profiles of compound 6, calculated with various DFT methods.

The solution electrochemistry of the fullerene-steroids hybrids 6-9 was investigated by cyclic voltammetry (CV) and Osteryoung Square Wave Voltammetry (OSWV). The redox potentials are summarized in Table 1. 
Table 1. Redox Potentials of fullerene derivatives 6-9 vs Ferrocene in THF (V). ${ }^{\mathrm{a}}$

\begin{tabular}{lllll}
\hline Compound & $\mathbf{E}^{\mathbf{1} / 2, \text { red }}$ & $\mathbf{E}^{2}{ }_{\mathbf{1} / 2, \text { red }}$ & $\mathbf{E}^{3}{ }_{\mathbf{1} 2 \text {, red }}$ & $\mathbf{E}^{\mathbf{4} / 2, \text { red }}$ \\
\hline $\mathbf{6}$ & -1.02 & -1.60 & -2.25 & $-2.78^{\mathrm{b}}$ \\
$\mathbf{7}$ & -0.98 & -1.55 & -2.16 & $-2.65^{\mathrm{b}}$ \\
$\mathbf{8}$ & -0.98 & -1.54 & -2.17 & $-2.64^{\mathrm{b}}$ \\
$\mathbf{9}$ & -0.94 & -1.51 & $-2.16^{\mathrm{b}}$ & $-2.67^{\mathrm{b}}$ \\
$\mathbf{C}_{\mathbf{6 0}}$ & $-0.90^{\mathrm{c}}$ & $1.49^{\mathrm{c}}$ & $-2.06^{\mathrm{c}}$ & $-2.56^{\mathrm{c}}$
\end{tabular}

${ }^{a}$ Working electrode: glassy carbon electrode; counter electrode: Pt; reference electrode: $\mathrm{Ag} / \mathrm{AgNO}_{3}$. Supporting electrolyte: $\mathrm{TBAPF}_{6}$. Scan rate: $0.1 \mathrm{Vs}^{-1} \cdot \mathrm{E}^{1 / 2}=\left(\mathrm{E}^{\mathrm{pa}}+\mathrm{E}^{\mathrm{pc}}\right) / 2$, where $\mathrm{E}^{\mathrm{pc}}$ and $\mathrm{E}^{\mathrm{pa}}=$ cathodic and anodic peak potentials, respectively. ${ }^{\mathrm{b}}$ From OSWV. ${ }^{\mathrm{c}}$ From reference 33, using $\mathrm{TBAClO}_{4}$ as supporting electrolyte.

All fulleropyrrolidine derivatives exhibit four quasi-reversible reduction waves in the investigated solvent window (Figure 1). As expected, these reduction values are cathodically shifted $(\Delta \mathrm{E}=0.12$ $0.04 \mathrm{~V}$ ) in comparison with the parent $\mathrm{C}_{60},{ }^{31}$ a consequence that stems from saturating a double bond of the $\mathrm{C}_{60}$ core, which raises the LUMO energy. In this sense, and in addition to the thoroughtful spectroscopic characterization carried out on these compounds and discussed above, the electrochemical studies further demonstrated the formation of fulleropyrrolidine monoadducts.

Figure 3. Cyclic voltammograms of 6 in THF, $0.1 \mathrm{M} \mathrm{TBAPF}_{6}$, with a scan rate of $0.1 \mathrm{~V} / \mathrm{s}$.

Furthermore, the absence of significant potential shifts with respect to other fulleropyrrolidine monoadducts indicate that there is essentially no effect of the steroidic unit on the electronic properties of the $\mathrm{C}_{60}$ core. $^{32}$

Inspection of the CD spectra shows that diastereoisomeric pairs 6, 7 and 8,9 give nicely opposite signed curves in the $430 \mathrm{~nm}$ region of the electronic spectra, thus confirming opposite configurations in the new stereogenic center (see Figure 4). This relevant UV-visible band is considered the fingerprint for all fullerene monoadducts at 6,6 junctions (between two fused hexagons) regardless of the nature of the organic addend saturating the double bond. In order to assigned the absolute configuration of the new stereogenic carbon formed on C2 of the pyrrolidine ring, we take into account the sector rule, ${ }^{33-35}$ which links Cotton effect (CE) associated with this diagnostic UV-vis 
band and the stereochemical environment around the 6,6 junction. Using this rule we have determined the absolute configuration of C2 for compounds $6(2 R), 7(2 S), 8(2 S), 9(2 R)$ (See Scheme 1 and Supporting information).
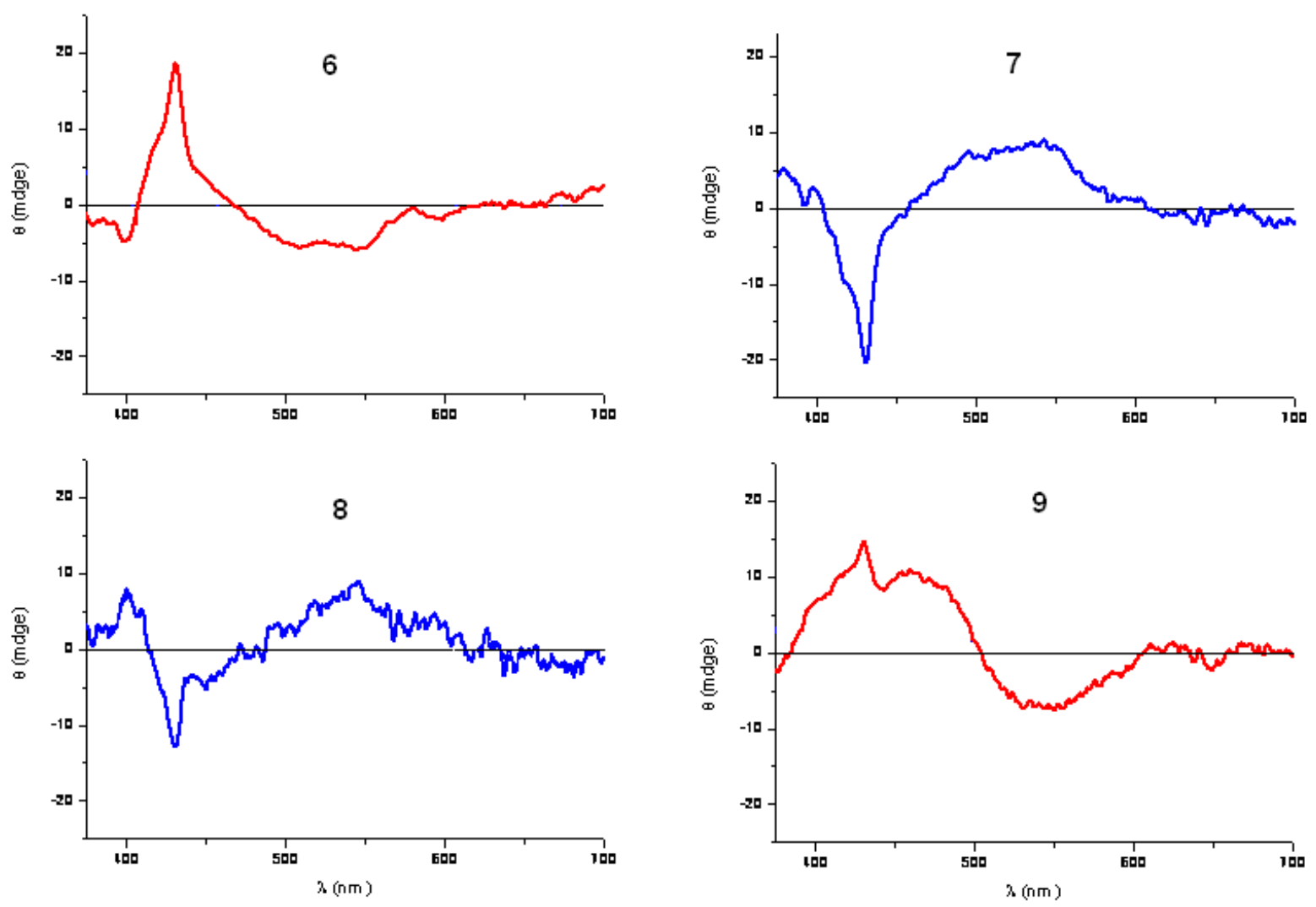

Figure 4. $\mathrm{CD}$ spectra of fulleroyrrolidines (6-9) in $\mathrm{CH}_{2} \mathrm{Cl}_{2}$ (conc, $4 \times 10^{-4} \mathrm{M}$ ).

\section{CONCLUSIONS}

We have carried out the synthesis of new [60]fullerene-steroid hybrids as functional chimeras (6, 7, 8, and 9) by using Prato's reaction of the corresponding steroid-containing formyl group (4 and 5) with $\mathrm{C}_{60}$. The reactions are sensitive to steric factors and $\mathrm{C}_{60}$ reacts with good diastereoselectivity with bulky chiral reagents. A thorough spectroscopic, computational and analytical study has allowed the chemical structures of the new fulleropyrrolidines to be unambiguously determined. The resulting chiral adducts exhibit chiroptical properties, with typical Cotton effects in CD spectra that can be used to assign the absolute configuration to fulleropyrrolidines. The new hybrid compounds (6, 7, 8, and 9), bearing fullerene and steroid units in the same molecule, can be considered promising functional chimeras, with potential biomedical applications 


\section{EXPERIMENTAL SECTION}

General: All reactions were performed using an atmosphere of argon and oven-dried glassware. Solvents were dried by standard procedures. All reagents were of commercial quality and were used as supplied unless otherwise specified. Reactions were monitored by thin-layer chromatography carried out on $0.25 \mathrm{~mm}$ silica gel plates (230-400 mesh). Flash column chromatographies were performed using silica gel (60 A, 32-63 $\mu \mathrm{m}$ ). FTIR spectra were recorded with a Tensor 27 (ATR device) spectrometer in $\mathrm{CHCl}_{3} .{ }^{1} \mathrm{H}$ NMR spectra were recorded at $700 \mathrm{MHz}$, and ${ }^{13} \mathrm{C}$ NMR at 175 MHz, with a Avance III instrument; the one-bond heteronuclear correlation (HMQC) and the longrange ${ }^{1} \mathrm{H}-{ }^{13} \mathrm{C}$ correlation (HMBC) spectra were obtained by use of the inv4gs and the inv4gslplrnd programs. HRMS-ESI spectra were recorded with an FTMS APEX Q-IV instrument at 4.7 T, and HRMS-MALDI (dithranol as matrix) in an Applied Biosystem 4700 Reflector machine. UV/Vis spectra were recorded in $\mathrm{CHCl}_{3}$. Microanalysis was performed with $2400 \mathrm{CHN}$ instrument. An Agilent 1100 high-performance liquid chromatography (HPLC) system was used to determine the purity of the compounds synthesized. A BuckyPrep column (column dimensions, 4.6 x 250 mm; flow rate $1.0 \mathrm{mLmin}^{-1}$, injection volume $15 \mu \mathrm{L}$, eluente mixture toluene:acetonitrile 9:1) was employed. The retention times ( $t$ Rs) and the peak areas (PAs) reported were determined at a wavelength of $320 \mathrm{~nm}$. Electrochemical measurements were performed with an Autolab PGStat 30 instrument with a three-electrode configuration system. The measurements were carried out with THF solutions [0.1 M in tetrabutylammonium hexafluorophosphate (TBAPF 6 )]. A glassy carbon electrode (3 mm diameter) was used as the working electrode, and a platinum wire and an $\mathrm{Ag} / \mathrm{AgNO}_{3}$ electrode were employed as the counter and the reference electrode, respectively. Ferrocene $(\mathrm{Fc})$ was added as an internal reference, and all the potentials were determined relative to the $\mathrm{Fc} / \mathrm{Fc}^{+}$couple. Both the counter and the reference electrodes were directly immersed in the electrolyte solution. The surface of the working electrode was polished with commercial alumina prior to use. Solutions were stirred and deaerated by bubbling argon for a few minutes prior to each measurements. Unless otherwise specified, the scan rate was $100 \mathrm{mV} / \mathrm{s}$. 
and employ larger-than-default numerical thresholds. Furthermore, the RI- and COSX-based techniques were also used to alleviate the computational cost when needed. The BLYP, B3LYP, and B2-PLYP exchange-correlation functionals, which allows to explore the dependence of the results upon sophistication of the underlying expressions, were always used with the corresponding dispersion correction (-D) for weakly overlapping molecular fragments.

\section{Synthesis of compounds.}

5 $\beta$-androstan-3,17-dione (2). This compound was prepared by following the method previously reported in the literature in $85 \%$ yield, m.p. $130-132{ }^{\circ} \mathrm{C}$. (lit. $\left.129-131{ }^{\circ} \mathrm{C}\right) .^{26}$

3a-acetoxy-5 $\beta$-androstan-17-one (3). This compound was prepared by following the method previously reported in the literature in $80 \%$ yield, m.p. $103-104{ }^{\circ} \mathrm{C}\left(\text { lit } 106-108{ }^{\circ} \mathrm{C}\right)^{27}$

3-Chloro-2-formyl-17-oxo-5 $\beta$-androstan-2-ene (4). To a stirred cold $\left(0-5{ }^{\circ} \mathrm{C}\right)$ mixture of phosphorus oxychloride $(1.6 \mathrm{ml})$ and dimethylformamide $(1.3 \mathrm{ml})$, a solution of $5 \beta$-androstan-3,17dione (2) (1.25 g, $9 \mathrm{mmol})$ in dichloromethane $(20 \mathrm{ml})$ was added dropwise. The reaction mixture was allowed to attain room temperature and then refluxed under argon for 18 hours. The mixture was added to a solution of sodium acetate (40 $\mathrm{g}$ in $100 \mathrm{ml}$ of water) and stirred at room temperature for one hour. The mixture was extracted with dichlorometane and the organic phase was washed twice with water and subsequently dried with anhydrous sodium sulfate. The organic extracted was concentrated and the solid obtained was purified by column chromatography using a mobile phase, cyclohexane-ethyl acetate (4:1). The product was isolated as a white solid, yield 78 \%, m.p. 140-142 ${ }^{\circ} \mathrm{C} . \mathrm{IR}\left(\mathrm{CHCl}_{3}\right) v_{\max } 2923,1738,1676,1625,1448,1149 \mathrm{~cm}^{-1} ;{ }^{1} \mathrm{H}$ NMR $\left.(700 \mathrm{MHz}), \mathrm{CDCl}_{3}\right) \delta$ 0.76 (s, 3H, $\left.\mathrm{CH}_{3}-\mathrm{C} 10\right), 0.83$ (m, 1H, H9), 0.88 (s, 3H, $\mathrm{CH}_{3}-\mathrm{C} 13$ ), 1.27 (m, 1H, H12), 1.27 (m, 1H, H14), 1.27 (m, 1H, H6), 1.42 (m, 1H, H11), 1.51 (m, 1H, H15), 1.57 (m, 1H, H5), 1.58 (m, 1H, H6), 1.62 (m, 1H, H8), 1.75 (d, $J=17.0 \mathrm{~Hz}, 1 \mathrm{H}, \mathrm{H} 1), 1.75$ (m, 1H, H11), 1.80 (m, 1H, H7), 1.84 (m, 1H, H12), 1.84 (m, 1H, H7), 1.90 (m, 1H, H15), 2.07 (m, 1H, H16), 2.35 (m, 1H, H4), 2.45 (m, 1H, H4), 2.44 (m, 1H, H16), 2.56 (d, $J=17.0 \mathrm{~Hz}, 1 \mathrm{H}, \mathrm{H} 1), 10.18$ (s, 1H, CHO); ${ }^{13} \mathrm{C}$ NMR (175 MHz, CDCl $\left.{ }_{3}\right)$

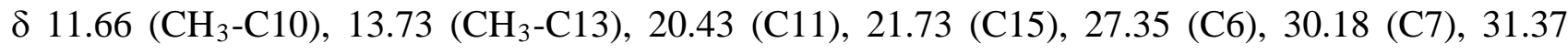


(C12), 34.88 (C8), 34.30 (C10), 35.76 (C16), 37.78 (C1), 40.24 (C4), 42.42 (C5), 46.63 (C13), 51.19 (C14), 56.43 (C9), 133.00 (C2), 149.57 (C3), 191.35 (CHO), 220.89 (C17). MS (ESI): 357.2 [M + $\mathrm{Na}^{+}$. Anal. Calcd. for: C, 71.73; H, 8.13. Found: C, 71.67; H, 8.20.

3- $\alpha$-acetoxy-17-chloro-16-formyl-5 $\beta$-androstan-16-ene (5). To a stirred cold $\left(0-5{ }^{\circ} \mathrm{C}\right)$ mixture of phosphorus oxychloride (10 mL) and dimethylformamide $(10 \mathrm{~mL})$, a solution of $3 \beta$-acetoxy-5 $\alpha$ androstan-17-one (2 g, $6 \mathrm{mmol})$ in chloroform (40 mL) was added dropwise. The reaction mixture was allowed to attain room temperature and then refluxed under argon for 5 hours. The mixture was added to a solution of sodium acetate ( $40 \mathrm{~g}$ in $100 \mathrm{ml}$ of water) and stirred at room temperature for one hour. The mixture was extracted with dichlorometane and the organic phase was washed twice with water and subsequently dried with anhydrous sodium sulfate. The organic extracted was concentrated and the solid obtained was purified by column chromatography using as mobile phase, cyclohexane- ethyl acetate (4:1). The product was isolated as a white solid, yield 50 \%, m. p. 130$\left.132{ }^{\circ} \mathrm{C} . \mathrm{IR}\left(\mathrm{CHCl}_{3}\right) v_{\max } 2939,1732,1673,1587,1243,1025 \mathrm{~cm}^{-1} ;{ }^{1} \mathrm{H} \mathrm{NMR}(700 \mathrm{MHz}), \mathrm{CDCl}_{3}\right) \delta$ 0.78 (m, 1H, H9), 0.87 (s, 3H, $\left.\mathrm{CH}_{3}-\mathrm{C} 10\right), 0.97$ (s, 3H, $\mathrm{CH}_{3}-\mathrm{C} 13$ ), 0.98 (m, 1H, H7), 1.05 (m, 1H, H1), 1.20 (m, 1H, H5), 1.30 (m, 1H, H6), 1.33 (m, 1H, H6), 1.37 (m, 1H, H4), 1.41 (m, 2H, H11, H12), 1.50 (m, 1H, H14), 1.51 (m, 1H, H2), 1.60 (m, 1H, H8),1.61 (m, 1H, H4), 1.72 (m, 1H, H1), 1.73 (m, 1H, H7), 1.83 (m, 1H, H2), 2.03 (s, 3H, CH $3-\mathrm{CO}), 1.84$ (m, 1H, H12), 2.04 (m, 1H, H15), 2.53 (m, 1H, H15), 4.70 (m, 1H, H3), 10.02 (s, 1H, CHO); ${ }^{13} \mathrm{C}$ NMR (175 MHz, CDCl 3 ) $\delta 12.30$ ( $\left.\mathrm{CH}_{3}-\mathrm{C} 10\right), 15.20$ ( $\left.\mathrm{CH}_{3}-\mathrm{C} 13\right), 20.60$ (C11), 21.46 ( $\left.\mathrm{CH}_{3}-\mathrm{CO}\right), 27.37$ (C4), 27.37 (C2), 28.20 (C6), 28.30 (C15), 31.00 (C7), 32.90 (C12), 33.38 (C8), 35.80 (C10), 36.46 (C1), 44.76 (C5), 50.90 (C13), 53.61 (C14), 54.42 (C9), 73.43 (C3), 136.42 (C16), 162.60 (C17), 170.68 (COO), 188.15 (CHO). MS (ESI): $401.2[\mathrm{M}+\mathrm{Na}]^{+}$. Anal. Calcd for $\mathrm{C}_{22} \mathrm{H}_{31} \mathrm{ClO}_{3}$ : C, 69.73; H, 8.25. Found: C, 69.66; $\mathrm{H}$, 8.18.

Synthesis of $\mathrm{N}$-methyl-2-substitutedpyrrolidino[ 3,4:1,2][60]fullerenes $(6,7,8,9)$. A mixture of $\mathrm{C}_{60}(0.15 \mathrm{mmol})$, $\mathrm{N}$-methylglycine $(0.76 \mathrm{mmol})$, and the corresponding chloroformyl steroid (4 or 5) in toluene $(250 \mathrm{~mL})$ under argon atmosphere was refluxed for $6 \mathrm{~h}$. The color of the solution changed from purple to brown. The solvent was removed under reduced pressure and the solid 
residue thus obtained was purified by column chromatography on silica gel, using $\mathrm{CS}_{2}$ to elute unreacted $\mathrm{C}_{60}$ and dichloromethane to elute the corresponding pyrrolidino[3,4:1,2][60]fullerene. Additional purification of these compounds was carried out by repetitive precipitation and centrifugation using hexane, methanol and diethyl ether as solvents.

\section{N-Methyl-2(R)-(3'-chloro-17'-oxo-(5ß-antrostan-2'-en-2-yl)pyrrolidino[3,4:1,2][60]}

fullerene (6). HPLC: BuckyPrep, toluene/acetonitrile (9:1), flow rate $1 \mathrm{~mL} / \mathrm{min}, t \mathrm{R}=8.71 \mathrm{~min}$. The purification of $\mathbf{6}$ was performed by column chromatography on silica gel with $\mathrm{CS}_{2}$ and dichlorometane as the eluents. This compound was obtained in $42 \%$ yield (57\% based on recovered $\left.\mathrm{C}_{60}\right) \cdot[\alpha]_{\mathrm{D}}{ }^{20}=+185$ (c $2 \times 10^{-4} \mathrm{CH}_{2} \mathrm{Cl}_{2}$ ). Brown solid. UV/Vis: $\lambda \max (\log \varepsilon)=425$ (3.70), 325 (4.31), 258 (4.52) nm. IR ( $\left.\mathrm{CHCl}_{3}\right) v_{\max }$ 2961, 2919, 2850, 1737, 1447, 1261, 1098, 802, 753, 665 $\mathrm{cm}^{-1} .{ }^{1} \mathrm{H}$ NMR (700 MHz, $\left.\mathrm{CDCl}_{3}\right) \delta 0.74$ (m, 1H, H9'), 0.93 (s, 3H, CH $\left.3-\mathrm{C} 13^{\prime}\right), 0.96$ (m, 1H, H7'), 1.06 (s, 3H, $\mathrm{CH}_{3}-\mathrm{C} 10^{\prime}$ ), 1.29 (m, 1H, H6'), 1.30 (m, 1H, H14'), 1.32 (m, 1H, H12'), 1.44 (m, 1H, H5’), 1.53 (m, 1H, H15'), 1.54 (m, 1H, H6’), 1.55 (m, 1H, H11'), 1.58 (m, 1H, H8`), 1.82 (m, 1H, H7'), 1.90 (m, 1H, H12'), 1.91 (m, 1H, H11'), 1.96 (m, 1H, H15'), 2.03 (d, $J=17.7$ Hz,1H, H1'), 2.08 (m, 1H, H16'), 2.30 (m, 1H, H4'), 2.39 (m, 1H, H4'), 2.46 (m, 1H, H16'), 2.75 (s, 3H, CH ${ }_{3}-\mathrm{N}$ ), 2.95 (d, $J=17.7 \mathrm{~Hz}, 1 \mathrm{H}, \mathrm{H} 1^{\prime}$ ), 4.18 (d, $J=9.4 \mathrm{~Hz}, \mathrm{H} 5$ pyrrolidine ring), 4.90 (d, $J=9.4 \mathrm{~Hz}, \mathrm{H} 5$ pyrrolidine ring), 5.30 (s, $1 \mathrm{H}, \mathrm{H} 2$-pyrrolidine ring). ${ }^{13} \mathrm{C} \mathrm{NMR}\left(175 \mathrm{MHz}, \mathrm{CDCl}_{3}\right) \delta 11.98\left(\mathrm{CH}_{3^{-}}\right.$ C10’), 13.78 (CH$\left.{ }^{-C}-3^{\prime}\right), 20.74$ (C11'), 21.80 (C15’), 27.54 (C6’), 30.12 (C7’), 31.44 (C12’), 35.36 (C10'), 35.80 (C8'), 35.85 (C16'), 39.33 (C4'), $40.39\left(\mathrm{CH}_{3}-\mathrm{N}\right), 41.11\left(\mathrm{C}^{\prime}\right), 43.08$ (C5'), 47.67 (C13'), 51.16 (C14'), 53.75 (C9'), 69.74 ( $\mathrm{Csp}^{3} \mathrm{C}_{60}$ ), 69.68 (C5 pyrrolidine ring), 75.45 (Csp ${ }^{3} \mathrm{C}_{60}$ ), 79.67 (C2 pyrrolidine ring), 128.32 (C2'), 133.43 (C3’), 135.65, 134.92, 136.77, 139.72, 139.98, $140.05,140.27,141.74,141.83,141.93,142.08,142.15,142.17,142.19,142.23,142.25,142.60$, $142.65,144.37,142.69,143.17,143.06,144.43,144.53,144.68,145.16,145.26,145.31,145.39$, 145.48, 145.52, 145.65, 145.80, 146.01, 146.03,, 146.06, 146.08, 146.19, 146.22146.39, 146.35, 146.64, 147.30, 153.75, 154.51, 154.54, 156.15, 221.14 (C17'). HRMS (ESI): $[\mathrm{M}+\mathrm{H}]^{+}=$ 1082.22424. Calculated for $\mathrm{C}_{82} \mathrm{H}_{33} \mathrm{ClNO}, 1082.22451$ 


\section{N-Methyl-2(S)-(3'-chloro-17'-oxo-(5 $\beta$-antrostan-2'-en-2-yl)pyrrolidino[3,4:1,2]}

[60]fullerene (7). HPLC: BuckyPrep, toluene/acetonitrile (9:1), flow rate $1 \mathrm{~mL} / \mathrm{min}, t \mathrm{R}=9.33 \mathrm{~min}$. The purification of 7 was performed by column chromatography on silica gel with $\mathrm{CS}_{2}$ and dichlorometane as the eluents. This compound was obtained in $31 \%$ yield (43\% based on recovered $\left.\mathrm{C}_{60}\right) \cdot[\alpha]_{\mathrm{D}}{ }^{20}=+75\left(\right.$ с $\left.2 \times 10^{-4} \mathrm{CH}_{2} \mathrm{Cl}_{2}\right)$. Brown solid. UV/Vis: $\lambda \max (\log \varepsilon)=425$ (3.70), $325(4.31)$, $258(4.52) \mathrm{nm} . \mathrm{IR}\left(\mathrm{CHCl}_{3}\right) v_{\max }$ 2925, 2850, 1734, 1544, 1460, 1373, 1081, 1022, 868, 801, 667 $\mathrm{cm}^{-1} .{ }^{1} \mathrm{H}$ NMR (700 MHz, $\left.\mathrm{CDCl}_{3}\right) \delta 0.56$ (s, 3H, $\left.\mathrm{CH}_{3}-\mathrm{C} 10^{\prime}\right), 0.87$ (s, 3H, $\left.\mathrm{CH}_{3}-\mathrm{C}^{\prime}{ }^{\prime}\right), 0.90$ (m, 1H, H9'), 1.04 (m, 1H, H7’), 1.25 (m, 1H, H6'), 1.31 (m, 1H, H12'), 1.32 (m, 1H, H11'), 1.32 (m, 1H, H14'), 1.51 (m, 1H, H8'), 1.52 (m, 1H, H15'), 1.57 (m, 1H, H6'), 1.72 (m, 1H, H5'), 1.84 (m, 1H, H7’), 1.85 (m, 1H, H11'), 1.87 (m, 1H, H12'), 1.97 (m, 1H, H15’), 2.10 (m, 1H, H16’), 2.23 (m, 1H, H1'), 2.29 (m, 1H, H4'), 2.41 (m, 1H, H4'), 2.48 (m, 1H, H16'), 2.84 (s, 3H, $\left.\mathrm{CH}_{3}-\mathrm{N}\right), 3.12$ (d, $J=$ 16.5 Hz,1H, H1'), 4.18 (d, $J=9.3 \mathrm{~Hz}, \mathrm{H} 5$ pyrrolidine ring), 4.94 (d, $J=9.3 \mathrm{~Hz}$, H5 pyrrolidine ring), 5.30 (s, 1H, H2 pyrrolidine ring). $\left.{ }^{13} \mathrm{C} \mathrm{NMR} \mathrm{(175} \mathrm{MHz,} \mathrm{CDCl}_{3}\right) \delta 11.68\left(\mathrm{CH}_{3}-\mathrm{C} 10^{\prime}\right), 13.86$ (CH3-C13'), 20.46 (C11'), 21.73 (C15’), 27.26 (C6’), 30.29 (C7’), 31.49 (C12’), 34.94 (C10’), 35.10 (C8'), 35.80 (C16’), 39.33 (C4'), $41.37\left(\mathrm{CH}_{3}-\mathrm{N}\right), 41.41$ (C1'), 43.10 (C5’), 47.70 (C13'), 51.70 (C14'), 54.30 (C9’), 69.89 ( $\mathrm{Csp}^{3} \mathrm{C}_{60}$ ), 70.02 (C5 pyrrolidine ring), 75.59 (Csp ${ }^{3} \mathrm{C}_{60}$ ), 79.26 (C2 pyrrolidine ring), 128.50 (C2’), 133.40 (C3’), 135.41, 134.93, 136.34, 137.01, 139.87, 139.35, 140.11, 140.33, 141.52, 141.81, 141.88, 141.90, 142.06, 142.10, 142.13, 142.17, 142.19, 142.22, 142.26, 142.28, 142.61, 142.66, 142.70, 143.06, 143.11, 144.37, 144.44, 144.59, 145.17, 145.23, 145.32, 145.38, 145.42, 145.44, 145.65, 145.67, 145.88, 146.03, 146.06, 146.12,146.19, 146.23, 146.29, 146.39, 146.48, 146.95, 147.28, 147.33, 152.92, 154.69, 154.80, 156.02, 221.17 (C17'). HRMS (ESI): $[\mathrm{M}+\mathrm{H}]^{+}=1082.22414$. Calculated for $\mathrm{C}_{82} \mathrm{H}_{33} \mathrm{ClNO}, 1082.22451$

\section{N-Methyl-2(R)-(3'- $\alpha$-acetoxy-17'-chloro-5 $\beta$-androstan-16-en-2-yl)pyrrolidino[3,4:1,2]}

[60]fullerene (8). HPLC: BuckyPrep, toluene/acetonitrile (9:1), flow rate $1 \mathrm{~mL} / \mathrm{min}-1$, $t \mathrm{R}=5.29$ min. The purification of $\mathbf{8}$ was performed by column chromatography on silica gel with CS2 and toluene as the eluents. This compound was obtained in $28 \%$ yield (36\% based on recovered $\mathrm{C}_{60}$ ). $[\alpha]_{\mathrm{D}}^{20}=+90\left(\right.$ с $\left.2 \times 10^{-4} \mathrm{CH}_{2} \mathrm{Cl}_{2}\right)$. Brown solid. UV/Vis: $\lambda \max (\log \varepsilon)=425$ (3.70), 325 (4.31), 258 
(4.52) nm. IR $\left(\mathrm{CHCl}_{3}\right) v_{\max }$ 2923, 2852, 2786, 1730, 1628, 1245, 1028, 1245, 1026, 757, $660 \mathrm{~cm}^{-1}$. ${ }^{1} \mathrm{H}$ NMR (700 MHz, $\mathrm{CDCl}_{3}$ ) $\delta 0.67$ (m, 1H, H9'), 0.76 (m, 1H, H7'), 0.87 (s, 3H, $\mathrm{CH}_{3}-\mathrm{C} 10^{\prime}$ ), 1.01 (td, $J=14.3 \mathrm{~Hz}, J=3.7 \mathrm{~Hz}, 1 \mathrm{H}, \mathrm{H} 1^{\prime}$ ), 1.08 (s, 3H, $\mathrm{CH}_{3}-\mathrm{C} 13^{\prime}$ ), 1.16 (m, 1H, H5'), 1.20 (m, 1H,

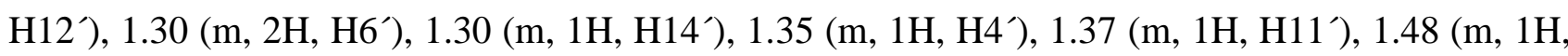
H2’), 1.59 (m, 1H, H4'), 1.60 (m, 1H, H8’), 1.61 (m, 1H, H11'), 1.68 (dt, J = 13.3 Hz, J = 3.3 Hz, 1H, H1'), 1.73 (m, 1H, H7'), 1.77 (m, 1H, H12'), 1.80 (m, 1H, H2'), 2.02 (s, 3H, $\mathrm{CH}_{3}-\mathrm{CO}$ ), 2.42 (m, 1H, H15'), 2.80 (m, 1H, H15'), 2.83 (s, 3H, $\mathrm{CH}_{3}-\mathrm{N}$ ), 4.18 (d, J= 9.7Hz, 1H, H5 pyrrolidine ring), 4.65 (m, 1H, H3), 4.90 (d, J= 9.7 Hz, 1H, H5 pyrrolidine ring), 5.05 (s, 1H, H2 pyrrolidine ring). ${ }^{13} \mathrm{C}$ NMR (175 MHz, $\left.\mathrm{CDCl}_{3}\right) \delta 12.17\left(\mathrm{CH}_{3}-\mathrm{C} 10^{\prime}\right), 15.54\left(\mathrm{CH}_{3}-\mathrm{C} 13^{\prime}\right), 20.69$ (C11'), $21.46\left(\mathrm{CH}_{3}-\mathrm{CO}\right)$, 27.38 (C2'), 28.30 (C6’), 31.16 (C7’), 32.07 (C15'), 33.90 (C4’), 33.80 (C8’), 34.23 (C12'), 35.70 (C10’), 36.30 (C1'), 44.62 (C5’), $48.60\left(\mathrm{CH}_{3}-\mathrm{N}\right), 48.90$ (C13’), 54.45 (C9’), 54.96 (C14'), 69.76 ( $\mathrm{Csp}^{3} \mathrm{C}_{60}$ ), 69.99 (C5, pyrrolidine ring), 73.42 (C3), 75.95 ( $\mathrm{Csp}^{3} \mathrm{C}_{60}$ ), 76.16 (C2 pyrrolidine ring), 133.60 (C16’), 135.31, 135.75, 136.37, 136.70, 139.42, 140.07, 140.23, 141.59, 141.79, 141.86, 141.99, 142.05, 142.08, 142.14, 142.15, 142.19, 142.21, 142.24, 142.60, 142.66, 142.71, 143.05, 143.19, 144.39, 144.45, 144.65, 144.71, 145.19, 145.28, 145.35, 145.38, 145.39, 145.42, 145.45, 145.46, 145.51, 145.61, 145.80, 146.00 (C17'), 146.05, 146.08, 146.13, 146.21, 146.22, 146.26, 146.34, 146.38, 146.45, 146.60, 146.67, 147.31, 147.36, 152.89, 153.96, 154.14, 155.96, 170.64 (COO). MALDI-TOF: $[\mathrm{M}+\mathrm{H}]^{+}=1126.245$. Calculated for $\mathrm{C}_{84} \mathrm{H}_{37} \mathrm{ClNO}_{2}, 1126.250 . \mathrm{ESI}[\mathrm{M}+\mathrm{H}]^{+}$ = 1126.25446. Calculated for $\mathrm{C}_{84} \mathrm{H}_{37} \mathrm{ClNO}_{2}, 1126.25128$.

\section{N-Methyl-2(S)-(3'- $\alpha$-acetoxy-17'-chloro-5 $\beta$-androstan-16-en-2-yl)}

pyrrolidino[3,4:1,2][60]fullerene (9). HPLC: BuckyPrep, toluene/acetonitrile (9:1), flow rate 1 $\mathrm{mL} / \mathrm{min}, t \mathrm{R}=7.03 \mathrm{~min}$. The purification of 7 was performed by column chromatography on silica gel with $\mathrm{CS}_{2}$ and toluene as the eluents. This compound was obtained in $47 \%$ yield (66 \% based on recovered $\left.\mathrm{C}_{60}\right) \cdot[\alpha]_{\mathrm{D}}{ }^{20}=+65\left(\right.$ c $\left.2 \times 10^{-4} \mathrm{CH}_{2} \mathrm{Cl}_{2}\right)$. Brown solid. UV/Vis: $\lambda \max (\log \varepsilon)=425(3.70)$, 325 (4.31), 258 (4.52) nm. IR $\left(\mathrm{CHCl}_{3}\right) v_{\max }$ 2923, 2853, 2789, 1734, 1628, 1258, 1092, 1024, 801, $706 \mathrm{~cm}^{-1} .{ }^{1} \mathrm{H}$ NMR (700 MHz, $\left.\mathrm{CDCl}_{3}\right) \delta 0.78$ (s, 3H, $\left.\mathrm{CH}_{3}-\mathrm{C} 13^{\prime}\right), 0.86$ (s, 3H, $\left.\mathrm{CH}_{3}-\mathrm{C}^{\prime} 0^{\prime}\right), 0.88$ (m, 1H, H9`), 1.10 (m, 1H, H1'), 1.26 (m, 1H, H5’), 1.29 (m, 2H, H6’), 1.32 (m, 1H, H7), 1.38 (m, 1H, 
H11'), 1.39 (m, 1H, H4'), 1.45 (m, 1H, H12'), 1.53 (m, 1H, H2'), 1.58 (m, 1H, H8'), 1.64 (m, 1H,

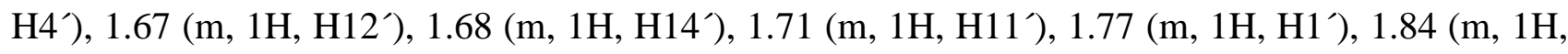
H7'), 1.85 (m, 1H, H2'), 2.05 (s, 3H, $\mathrm{CH}_{3}-\mathrm{CO}$ ), 2.15 (m, 1H, H15’), 2.80 (m, 1H, H15’), 2.80 (s, 3H, $\left.\mathrm{CH}_{3}-\mathrm{N}\right), 4.72$ (m, 1H, H3'), 4.08 (d, J= 9.0 Hz, 1H, H5-pyrrolidine ring), 4.18 (d, J= 9.0 Hz, 1H, H5-pyrrolidine ring), 5.02 (s, $1 \mathrm{H}, \mathrm{H} 2$ pyrrolidine ring). ${ }^{13} \mathrm{C} \mathrm{NMR}\left(175 \mathrm{MHz}, \mathrm{CDCl}_{3}\right) \delta 12.29$ ( $\left.\mathrm{CH}_{3}-\mathrm{C} 10^{\prime}\right), 16.18\left(\mathrm{CH}_{3}-\mathrm{C} 13^{\prime}\right), 20.94$ (C11'), $21.43\left(\mathrm{CH}_{3}-\mathrm{CO}\right), 27.54$ (C2'), 29.94 (C6'), 32.17

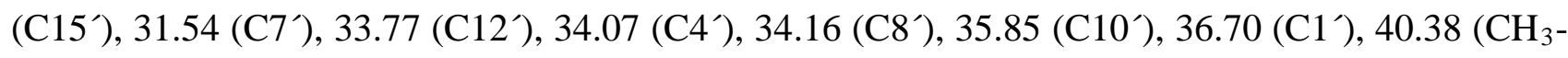
N), 45.06 (C5’), 49.19 (C13’), 55.68 (C14’), 54.80 (C9’), $69.84\left(\mathrm{Csp}^{3} \mathrm{C}_{60}\right.$ ), 69.67 (C5 pyrrolidine ring), 71.51 (C3’), 75.54 ( $\mathrm{Csp}^{3} \mathrm{C}_{60}$ ), 76.49 (C2 pyrrolidine ring), 133.36 (C16), 135.47, 135.80, 136.38, 136.88, 139.50, 140.11, 140.14, 140.32, 141.85, 141.90, 141,95, 142.05, 142.14, 142.20, 142.23, 142.30, 142.64, 142.68, 142.71, 142.73, 143.08, 144.39, 144.47, 144.61, 144.72, 145.19, 145.25, 145.35, 145.41, 145.48, 145.53, 145.64, 145.78, 146.04, 146.06, 146.09, 146.12, 146.23, 146.31, 146.35, 146.37, 146.54, 147.31 (C17’), 147.49, 153.36, 154.07, 154.31, 155.09, 170.45 (COO). ESI: $\left[\mathrm{M}+{ }^{`} \mathrm{H}\right]+=1126.25072$. Calculated for $\mathrm{C}_{84} \mathrm{H}_{37} \mathrm{ClNO}_{2}, 1126.25128$

\section{Supporting Information}

Spectral data for all compounds, HPLC chromatograms of the reactions mixture and pure products, absolute configuration assignement, and xyz coordinates (B3LYP-D3/SVP) of the atropoisomers found (6). This material is available free of charge via the Internet at http://pubs.acs.org.

\section{ACKNOWLEDGMENTS}

Financial support by the Ministerio de Ciencia e Innovación (MINECO) of Spain (CTQ2011-24652, CTQ2011-27253, PIB2010JP-00196, and CSD2007-00010 projects CAM (Madrisolar-2)) is acknowledged; A.R. thanks to UCM for finantial support; M.S. is indebted to Programa del Grupo Santander 2012.

\section{REFERENCES}


(1) (a) Hirsch, A.; Brettreich, M. The Chemistry of Fullerenes, Wiley-VCH: Weinheim, Germany, 2005. (b) Martín. N. Chem. Commun. 2006, 2093-2104. (c) Martín, N.; Altable, M.; Filippone, S.; Martín-Domenech. A. Synlett 2007, 3077-3095.

(2) (a) Maggini, M.; Scorrano, G.; Prato, M. J. Am. Chem. Soc. 1993, 115, 9798-9799. (b) Prato, M.; Maggini, M. Acc. Chem. Res. 1998, 31, 519-526.

(3) Filippone, S.; Maroto, E. E.; Martín-Domenech, A.; Suárez, M.; Martín, N. Nat. Chem. 2009, 1, 578-582.

(4) Maroto, E. E.; de Cozar, A.; Filippone, S.; Martín-Domenech, A.; Suárez, M.; Cossío F.P.; Martín, N. Angew. Chem. Int. Ed. 2011, 50, 6060 -6064.

(5) Sawai, K.; Takano, Y.; Izquierdo, M.; Filippone, S.; Martín, N.; Slanina, Z.; Mizorogi, N.; Waelchli, M.; Tsuchiya, T.; Akasaka, T.; Nagase, S. J. Am. Chem. Soc., 2011, 133, 17746-17752.

(6) Maroto, E. E.; Filippone, S.; Martín-Domenech, A.; Suárez, M.; Martín, N. J. Am. Chem. Soc. 2012, 134, 12936-12938.

(7) Novello, F.; Prato, M.; Da Ros, T.; De Amici, M.; Bianco A.; Toniolo, C.; Magginia M. Chem. Commun., 1996, 903-904.

(8) (a) Illescas, B.; Rife, J.; Ortuno, R. M.; Martin, N. J. Org. Chem. 2000, 65, 6246-6248. (b) Illescas, B. M.; Martín, N.; Poater, J.; Solá, M.; Aguado, G. P.; Ortuño, R. M. J. Org. Chem. 2005, 70, 6929-6932.

(9) Campidelli, S.; Bourgun, P..; Guintchin, B.; Furrer, J. Evans, S.; Saez, I. M.; Goodby, J. W.; Deschenaux, D. J. Am.Chem. Soc. 2010, 132, 3574-3581.

(10) Ioutsi, V. A.; Zadorin, A. A.; Khavrel, P.A.; Belov, N. M.; Ovchinnikova, N. S.; Goryunkov, A. A.; Kharybin, O. N.; Nikolaev, E. N.; Yurovskaya, M. A.; Sidorov, L. N. Tetrahedron, 2010, 66, 3037-3041.

(11) (a) Smith, A. L.; Korobov, M. V. Book of Abstracts, $218^{\text {th }}$ ACS National Meeting, New Orleans, Aug. 22-26 (1999), MTLS-024. (b) Beck, M. T.; Mandi, G.; Keki, S. Proceedings Electrochemical Society 1995, 95-10, Proceedings of the Symposium on Recent Advances in the 
Chemistry and Physics of Fullerenes and Related Materials, 1995, 1510-1518. (c) An, Y.; Ellis, G. A.; Viado, A. L.; Rubin, Y. J. Org. Chem. 1995, 60, 6353-6361.

(12) Pantarotto. D.; Tagmatarchis, N.; Bianco, A.; Prato M. Minirev. Med. Chem. 2004, 4, 805814.

(13) Da Ros, T.; S., G.; Boutorine, A.; Prato, M. Australian J. Chem. 2001, 54, 223-224.

(14) MacFarland, D.; Zhang, Jing; Zhou, Zhiguo; Lenk, Robert P.; Wilson, Stephen R. U.S. Pat. Appl. Publ. 2008, US 20080214514 A1 20080904.

(15) Itoh, T.; Mishiro, M.; Matsumoto, K.; Hayase, S.; Kawatsura, M.; Morimoto, M. Tetrahedron 2008, 64, 1823-1828.

(16) Coro, J.; Rodríguez, H.; Rivera, D. G.; Suárez, M.; Molero, D.; Herranz, M. A.; MartínezÁlvarez, R.; Filippone, S.; Martín, N. Eur. J. Org. Chem. 2009, 4810-4817.

(17) Raeside J. I.; Renaud R. L.; Marshall D. E. J. Steroid Biochem. Mol. Biol. 1992, 42, 113-120.

(18) Gupte, S. A.; Tateyama, M.; Okada, T.; Oka, M.; Ochi, R. J Mol Cell Cardiol. 2002, 34, 679688.

(19) Merlani M. I.; Davitishvili M. G.; Nadaraia N. Sh.; Sikharulidze M. I.; Papadopulos K.; Chem. Nat. Comp. 2004, 40, 144-146.

(20) Doss S. H.; Louca N. A.; Elmegeed G. A.; Mohareb R. M. Arch. Pharm. Res. 1999, 22, 496501.

(21) Ishi-I, T.; Shinkai, S. I. Tetrahedron 1999, 55, 12515-12530.

(22) Li, L.; Hu, Y.; Wu, Y.; Wu, Y.; Yue, J.; Yang, F. J. Chem. Soc. Perkin Trans. 1 2001, 617621.

(23) Fong, R, II; Schuster, D. I.; Wilson, S. R. Org. Lett. 1999, 1, 729-732.

(24) Schuster, D. I. Carbon 2000, 38, 1607-1614.

(25) Bjelakovic, M. S.; Godjevac, D. M.; Milic, D. R. Carbon 2007, 45, 2260-2265.

(26) MacFarland, D.; Zhang, J.; Zhou, Z.; Lenk, R. P.; Wilson, S. R. U. S. Pat. Appl. Publ. 2008, US 2008214514 A1 20080904. 
(27) Reyes-Moreno, M.; Fuente-Hernández, A.; Ruiz-García, J. A.; Álvarez-Ginarte, Y. M.; Vélez-Castro, H.; Fernández-Villalobo, A.; Montiel-Smith, S.; Meza-Reyes S.; Sandoval-Ramírez, J. J. Mex. Chem. Soc. 2007, 51, 232-236.

(28) Reyes-Moreno, M.; Ruiz-Garcia, J. A.; Ibarra-Reyes, Y.; Fuente-Hernandez, A.; VélezCastro, H.; Hernandez-Balmaseda, I.; Martínez-Hormaza, I.; Rodeiro-Guerra, I.; Sandoval Ramírez, J.; Meza Reyes, S.; Montiel-Smith. S. Eur. J. Med. Chem. 2009, 44, 4567-4571.

(29) Maroto, E.; Filippone, S.; Martín-Domenech, A.; Suárez, M.; Martín, N.; Martínez-Álvarez, R. J. Mass. Spectrom. 2011, 46, 1016-1029.

(Ref1) Grimme, S. J. Comput. Chem. 2006, 27, 1787-1799.

(Ref2) Grimme, S.; Antony, J.; Ehrlich, S.; Krieg, H. J. Chem. Phys. 2010, 132, 154104.

(Ref3) Grimme, S. J. Chem. Phys. 2006, 124, 34108.

(Ref4) Schwabe, T.; Grimme, S. Acc. Chem. Res. 2008, 41, 569-579.

(30) Ajamaa, F.; Figueira Duarte, T. M.; Bourgogne, C.; Holler, M.; Fowler, P. W.; Nierengarten, J.-F. Eur. J. Org. Chem. 2005, 3766-3774.

(31) Echegoyen, L. E.; Herranz, M. A.; Echegoyen, L. in Fullerenes, Enciclopedia of Electrochemistry, Vol. 7, Inorganic Electrochemistry, Geiger W.E., Pickett, C., John Wiley and Sons, 2006.

(32) For an example where an steroidic unit acts as a brigge preventing the electronic communication between two electroactive units, see: Guldi, D. M.; Maggini, M.; Menna, E.; Scorrano, G.; Ceroni, P.; Marcaccio, M.; Paolucci, F., Roffia, R. Chem. Eur. J. 2001, 7, 1597-1605.

(33) Wilson, S. R.; Lu, Q.; Cao, J.; Wu, Y.; Welch C. J.; Schuster D. I. Tetrahedron 1996, 52, $5131-5142$.

(34) Tan, X.; Schuster D. I.; Wilson, S. R. Tetrahedron Lett. 1998, 39, 4187-4190.

(35) Eliel, E. L.; Wilen, S. H. Stereochemistry of Organic Compounds, Ch. 12 Wiley, 1994.

(Ref5) Neese, F. WIREs Comput. Mol. Sci. 2012, 2, 73-78. 